\title{
Twitter como mídia estratégica de marca: um estudo de caso
}

\author{
José Alberto Carvalho dos Santos Claro \\ Universidade Metodista de São Paulo - Umesp - albertoclaro@albertoclaro.pro.br \\ Possui graduação em Administração de Empresas pela Universidade \\ Católica de Santos (1992), mestrado em Administração pela Umesp (1998) \\ e doutorado em Comunicação Social pela mesma instituição (2002). Atualmente, \\ é professor e pesquisador em dedicação integral do Programa de \\ Mestrado em Administração da Umesp
}

Barbara Arruda

Universidade Católica de Santos - UniSantos - arruda.babi@gmail.com Tem formação em Comunicação Social - Jornalismo e é especialista em Marketing, ambos pela Universidade Católica de Santos. É jornalista e consultora de marketing digital na Baixada Santista.

\begin{abstract}
Resumo
O uso das mídias sociais por empresas para se comunicar junto ao público cresce em importância nos processos de comunicação e difusão de marca. Este trabalho objetiva analisar o uso do Twitter como mídia estratégica de marca, gerando fidelização do cliente. A metodologia utilizada foi o estudo de caso do perfil @sigamelissa da marca Melissa. Percebeuse que o caso estudado obteve resultados interessantes, apesar de apresentar algumas lacunas em sua utilização, e conseguiu melhorar o relacionamento e consequentemente, o fortalecimento da marca.
\end{abstract}

\section{Palavras-chave}

Mídias Sociais. Twitter. Estudo de caso.

\begin{abstract}
The use of social media by companies to communicate with the public is increasingly important in the processes of communication and brand difusion. This paper analyzes the use of Twitter as a strategic media brand, creating customer loyalty. The methodology used was case study profile @sigamelissa of Melissás brand. It was noticed that the case study had interesting results with its audience, despite a few shortcomings in its use, and managed to improve the relationship and consequently, the strengthening of the brand.
\end{abstract}

\section{Keywords}

Social Medias. Twitter. Case Study.

Artigo recebido em 27/05/2012

Aprovado em 09/09/2012 


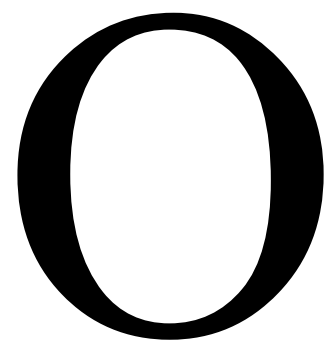

relacionamento deixa de ser somente pessoal e passa a tratar o fortalecimento de marca também no mundo virtual, baseando-se em redes de interesses, expectativas e realizações com os formadores de opinião. Vivem-se tempos de compartilhamento de informação, portanto, não basta ter o conhecimento, mas distribuí-lo de forma correta nos canais e mídias certos, fazendo com que a empresa ou a marca tenham a repercussão necessária para atingir seu público. Afirma Garbin (2003) que a internet não pode ser mais considerada apenas para busca ou troca de informações, ou então, somente para promover encontros virtuais, mas sim um local propício para a produção de conteúdo, de conhecimento.

A excelência de uma boa comunicação empresarial liga-se profundamente com a idéia de relacionamento e com isso, as chamadas novas mídias, somam neste conceito de disseminação de informação através das redes sociais. Ter pessoas influenciando pessoas por meio de recursos tecnológicos é visto por Rodriguez (2009) como a definição de mídias sociais, e complementa afirmando que esses recursos foram desenvolvidos para permitir a interação social a partir do compartilhamento e da criação colaborativa de informação. As organizações precisam se reestruturar e algumas delas já estão passos à frente, enxergaram essas novas oportunidades de comunicação e ampliação de mercado para construir bases sólidas com seus clientes e consumidores (DOMINGUES, 2004). E entre as novas mídias, uma se destaca pelo alcance e pela capacidade de proliferação de informação em um curto espaço de tempo: o Twitter. Um microblog visto como uma mistura de blog com rede social e mensagens instantâneas (ZAGO, 2008), um espaço no qual, 140 caracteres colocam uma marca em evidência positiva ou negativamente em questão de minutos. Outros tantos também fazem parte dessa nova forma de comunicação, e entre os principais temos Facebook, Orkut e Linkedin. Alguns, inclusive, específicos para determinados públicos. Silva e Valls (2012) ao apresentarem os elementos da gestão do conhecimento, os relacionaram com o Twitter e concluíram que ele é uma ferramenta adequada para a criação e distribuição de conhecimento. Dias e Couto (2011) apontam o fato de que a sociabilidade nessas redes sociais não possuem as mesmas condições de produção que a sociabilidade presencial, pois o imaginário é regido de formas diferentes nesses espaços.

Percebe-se que as pessoas podem agir de maneira diferente nesses dois ambientes: o virtual e o real. Já Bernardo e Speck (2010) consideraram o Twitter como construtor de um novo tipo de "cibersocialidade" a partir das novas relações sociais lá construídas 
e chamam a atenção para o aumento da mediação computacional na comunicação cotidiana. O Twitter é uma das mídias sociais que assume a posição estratégica de disseminação de informação em um ambiente que gera relacionamento, e não somente uma rede social, já que ainda de acordo com a definição de Rodriguez (2009), as redes sociais entram na categoria de relacionamentos e possuem como finalidade principal conectar pessoas. Por isso, mesmo que com finalidades distintas em algum âmbito, outras mídias sociais também acabam promovendo relacionamento além de suas funcionalidades básicas. Em pouco tempo, o Twitter se tornou uma das principais mídias sociais utilizadas e como definem Comm e Burge (2009), ele é o mais poderoso serviço de microblog disponível e deve-se dar a devida atenção. Sua força é tão evidente que recentemente a pergunta que havia no topo da página do Twitter: "O que você está fazendo?” foi substituída pelo “O que está acontecendo?” (TWITTER, 2012).

Por isso, a utilização do microblog vai depender da estratégia de relacionamento de marca que a empresa irá empregar com seus seguidores, atendendo suas necessidades por informações, mantendo um feedback direto, proporcionando o fortalecimento da marca e gerando, consequentemente, uma fidelização mais eficaz. Também é necessário afirmar que ele é uma ferramenta que deva ser utilizada em conjunto com outras mídias sociais para obter melhores resultados pelas empresas, pois assim o Twitter ganha ainda mais força e se torna fundamental na questão de diferencial no que se refere à distribuição de informação e fortalecimento da marca (HENDERSON, 2010).

Considerando todos estes fatores, o objetivo principal deste estudo é identificar se realmente o Twitter é uma mídia social adequada para o fortalecimento da marca. Como objetivos específicos delinearam-se: analisar o Twitter da @sigamelissa para se fazer um levantamento quantitativo do seu uso; verificar qualitativamente os resultados da utilização do Twitter da @sigamelissa; e finalmente, contribuir para o referencial teórico e gerencial sobre o objeto de estudo. Mesmo com toda literatura disponível sobre as estratégias de marca, a eficiência da comunicação na internet, as mídias sociais e os novos paradigmas da comunicação no ciberespaço, não se encontrou um estudo que faça um cruzamento sobre a utilização do Twitter para fortalecimento da marca. Observado isso, justifica-se a realização deste estudo específico sobre o tema para servir de orientação a futuros estudos. Como estratégia metodológica foi escolhida a realização do estudo de caso do Twitter da marca Melissa (@sigamelissa). A partir dos resultados obtidos, pôde-se perceber que se pode criar um relacionamento mais 
Estudos em Jornalismo e Mídia - Vol. 9 № 2 - Julho a Dezembro de 2012

eficiente, utilizando-se as mídias sociais, em especial o Twitter, como uma ferramenta estratégica para melhorar o desempenho e fortalecer a marca no ciberespaço.

\section{Referencial teórico}

Uma das formas de fortalecimento de marca é o marketing de relacionamento, que garante uma relação próxima e estreita com seu público-alvo. Kotler (2006) afirma que o marketing de relacionamento constrói uma rede que não só envolve clientes, mas também colaboradores, fornecedores, distribuidores, sociedade, etc., como um todo capaz de influenciar positivamente a imagem de uma empresa. Por isso, o autor defende que um dos principais objetivos do marketing de relacionamento é desenvolver relações profundas e duradouras. Outros autores, como Bretzke (2000) e McKenna (1999), também defendem o seu uso como ferramenta para criar melhores experiências para todos os envolvidos em uma transação. Uma marca está além daquilo que podemos ver e tocar. Ela está ligada a emoções, sensações e desejos. Transformar uma oferta em uma marca conhecida, revestida de sonhos e ideais, usando-se ferramentas como o Twitter deve ser feito de forma simples, pois, "os 140 caracteres do Twitter desafiam todos as sermos mais concisos" nos ensina Wheeler (2012, p. 37). Ela diz que "por trás de toda a marca de sucesso, há uma pessoa apaixonada, inspirando os outros a ver o futuro de outro ângulo" (p. 42). Inclusive, a autora, relaciona sustentabilidade, mídias sociais, transparência e design thinking às marcas, como se fossem indissociáveis e que são “ideias que se tornaram comuns” (WHEELER, 2012, p. 79).

Há uma necessidade de se visar não somente as mídias tradicionais como também as novas mídias que acompanham essa nova geração de consumidores desde seu nascimento. Dentro deste contexto, o advento das novas tecnologias da informação veio para auxiliar na exploração de novos mercados, além de ampliar o alcance da comunicação organizacional. Segundo Velloso (2008, p. 1), “o ambiente das ações e interações dos sujeitos sociais são determinantes para a criação da cibercultura contemporânea". Nesse espaço virtual, o que se coloca na rede se transforma em notícia, as mídias sociais ganham força na comunicação junto aos novos consumidores, e consequentemente em opinião, ajudando ou não a imagem de uma empresa ou marca. Essa reciprocidade instantânea faz com que as mídias sociais assumam um papel importante nos dias atuais dentro das organizações. Há a corrente teórica que não separa o real do virtual, mas sim o atual (LEVY, 1996; 1999). 
Estudos em Jornalismo e Mídia - Vol. 9 № 2 - Julho a Dezembro de 2012

O Twitter permite o envio de mensagens com 140 caracteres por Short Message Service (SMS), Instant Messenger (IM), pela web, internet móvel ou por aplicativos feitos a partir da API (Application Programming Interface ou Interface de Programação de Aplicações) do sistema. Ele foi criado pela empresa Obvious, em São Francisco (EUA) e lançado para o público no dia 13 de julho de 2006 (ZAGO, 2008). Tem o poder de disseminar ideias, trocar informações, multiplicar conhecimentos e relacionar várias pessoas ao mesmo tempo em questão de segundos. De Salvi (2009) relata que no Twitter é possível identificar tendências, analisar a concorrência, antecipar os hábitos em constante mudança e se aproximar dos consumidores. As redes sociais são sensíveis à comunicação boca a boca e ao relato das experiências desses membros e isso gera mais envolvimento emocional com a marca (DE SALVI, 2009). Esse crescimento e popularidade do microblog e o seu uso como gerador de oportunidade de negócios foi alvo de pesquisa realizada por Thoring (2011), que analisou os padrões de uso e o conteúdo gerado por uma grande editora britânica e, ao final, percebeu que o tamanho da empresa afeta o uso do Twitter em geral, o que provoca um baixo controle sobre o que é escrito. De acordo com uma pesquisa realizada pela Bullet (2010), agência de marketing promocional, as pessoas confiam nas opiniões e dicas espalhadas no Twitter, levando isso em conta para o consumo ou não de determinado produto. A popularização do serviço, sobretudo no Brasil, e como este pode ser utilizado como ferramenta de comunicação pessoal ou, mesmo, corporativa foi objeto de estudo de Cardozo (2009). Ela constatou por meio de pesquisa exploratória e documental sobre redes sociais na Internet que a sua utilização gera maior credibilidade na difusão de informações, sejam pessoais, sejam corporativas. Além de fornecer informações sobre a empresa, colocar links que direcionam para seus sites institucionais, blogs e afins, ou até mesmo criar assuntos para estimular debates entre os seguidores sobre a marca, as empresas também podem criar promoções, ofertas e descontos especiais para atrair mais seguidores e estimular os já existentes, tratando-os de uma forma diferenciada e influenciando, desta forma, o comportamento desse consumidor (CARVALHO, 2009). Vale lembrar que é apenas mais uma ferramenta para uma venda direta e existe a necessidade específica de se ter um portal de vendas online bem estruturado (CONSONI; OIKAWA, 2009). A questão abrange o envolvimento emocional do consumidor, fazendo com que ele se sinta parte da equipe e que suas opiniões sejam levadas em consideração na decisão final. "Um sólido grupo de seguidores é também um recurso (...) (valioso) porque representam uma gigantesca fonte de informações” (COMM; BURGER, 2009, p. 135). 
Da mesma forma que as opiniões positivas têm que ser levadas em consideração pela empresa e as reclamações sobre o produto também devem ser lidas e respondidas. Mesmo não sendo um canal de SAC (Serviço de Atendimento ao Consumidor), o seguidor vai se sentir à vontade para apontar os defeitos, erros ou má prestação de serviço via Twitter e se a empresa não estiver preparada para monitorar essas críticas, ou então, ignorar os comentários expostos na rede, não oferecendo o suporte adequado para atender a essa demanda, as consequências podem ser desastrosas, gerando rapidamente uma publicidade negativa (MÍDIAS SOCIAIS, 2010). A melhor forma de conter os discursos que prejudicam a marca é sempre a comunicação transparente. Verificar se o tweet tem fundamento, sanar os possíveis erros ou falhas é o melhor caminho para mostrar que a empresa está preparada para trabalhar em conjunto com o consumidor, verificando suas queixas, suas necessidades, adequando a mensagem e depois responder a reclamação no próprio Twitter, para que o grupo veja que no relacionamento entre empresa/consumidor existe diálogo, porque um tweet negativo pode prejudicar seriamente a imagem de uma marca (COMM; BURGER, 2009). Os consumidores mais jovens são acostumados com a comunicação instantânea e em rede, familiarizados com o fluxo de informação e os avanços da tecnologia (LAB SSJ, 2010).

Alunos jovens egressos de cursos de pós-graduação lato sensu foram estudados por Claro et al. (2010) em questões relativas a informações sobre hábitos de consumo, carreira e estilo de vida, bem como formas de utilização do tempo de lazer. Eles perceberam que o tempo que seria destinado ao lazer é despendido nas redes sociais. Segundo a pesquisa da Bullet (2010), o perfil dos usuários do Twitter é de jovensadultos numa faixa etária entre 21 a 30 anos, solteiros e com grau de escolaridade elevado, são heavy users de internet, e utilizam também outras mídias sociais como Orkut, Youtube, Facebook, Flickr, Last.fm e Google Reader. Além disso, a pesquisa revela o hábito dos usuários de replicar os tweets (no senso comum chamado de 'dar um RT') para seus seguidores se a mensagem possuir uma ideia ou um link interessante para compartilhar ou até mesmo gerar discussões sobre determinado assunto (BULLET, 2010). Isso comprova que o Twitter além de gerar compartilhamento de informações, também fornece em tempo real um panorama de assuntos principais em discussão. Os seguidores de uma marca no microblog tornam-se formadores de opinião, pois usam a ferramenta tanto para criticar como para elogiar. Outra forma de potencializar o poder de ação do Twitter é que ele seja utilizado em conjunto com outros recursos virtuais como, por exemplo, blog, site institucional e loja virtual. Desta maneira, a estratégia 
digital de uma empresa ganharia mais força na promoção da marca, criando uma campanha online e direcionando os consumidores aos outros sites da empresa. É possível saber que tipo de tweets geram mais respostas e mais retweets. "Quais respostas de outros 'twitteiros' atraem mais seguidores para você", afirmam Comm e Burger (2009, p. 201). Isso é importante, porém, não é o suficiente. É necessário observar, testar, rastrear, verificar registros no servidor, além de se usar aplicativos que irão fornecer maiores informações sobre os resultados dos tweets na rede, e, com isso, sobre a repercussão da marca. O monitoramento deve-se estender aos outros sites da empresa, blog e lojas virtuais para ver se o número de visitações aumentou ou diminuiu, se gerou procura por informações, se impulsionou as vendas, etc. Rodriguez (2009) afirma que em virtude da exposição que as marcas ganham no microblog, esse ambiente se torna importante para a construção de marcas e interação com os púbicos.

Ressalta-se aqui a preocupação com o fato de haver pouca produção científica a respeito do tema, pincipalmente no Brasil, mas, mesmo internacionalmente isso é visto como algo que precisa ser resolvido rapidamente. Corroborando com essa preocupação, Burton e Soboleva (2011) atestaram a baixa produção teórica e empírica na análise do microblog pelas organizações. Então resolveram comparar doze perfis de empresas americanas e australianas, com base em modelos de comunicação interativa. Os resultados apontam as diferentes maneiras de se utilizar a ferramenta Twitter e sua capacidade interativa para se comunicar com os púbicos organizacionais. Perceberam também a falta da consciência e coerência estratégica de sua utilização (BURTON; SOBOLEVA, 2011). Finalmente, esta revisão teórica teve a preocupação de contribuir para o embasamento desta pesquisa e também para o alinhamento em termos de necessidades de pesquisas futuras a respeito da temática.

\section{Metodologia}

O perfil no Twitter escolhido para ser estudado foi o @sigamelissa (2010), da marca de calçados plásticos Melissa, pertencente ao grupo Grendene, criada na década de 80. Além da utilização de referenciais teóricos expostos anteriormente, foi percebido pelos autores a necessidade do desenvolvimento de um estudo de caso, conforme ensina Yin (2005). Procurou-se analisar o conteúdo postado, fazendo uma relação com a imagem da marca, observando a questão do feedback com o público e as questões da construção do relacionamento, fortalecimento da marca e geração de fidelidade. Levando em consideração o pouco material teórico-empírico sobre o Twitter e o seu uso 
Estudos em Jornalismo e Mídia - Vol. 9 № 2 - Julho a Dezembro de 2012

para fortalecimento da marca, um estudo de caso é a forma de pesquisa mais apropriada ao atendimento dos objetivos deste estudo. Dentro desta perspectiva, a análise do Twitter@sigamelissa responde a essas perguntas iniciais e ainda gera a oportunidade para outras respostas, formalizando um conjunto de observações relevantes deste estudo para a aplicação na prática do mercado, pois está focada em eventos contemporâneos, premissa de um estudo de caso (CAMPOMAR, 1991; YIN, 2005). O estudo de caso foi de natureza global com a coleta dos dados por meio de literatura específica, entrevista com a responsável pela manutenção de conteúdo do Twitter@sigamelissa e obtenção de dados institucionais da empresa. Vale salientar que além do perfil@ @sigamelissa, a empresa também possui o Twitter da loja online@LojaMelissa, o site institucional (http://www.melissa.com.br/), o blog (http://www.melissa.com.br/blog/) e a loja virtual (http://www.lojamelissa.com.br/). Estes canais foram estudados nesta análise apenas de forma complementar.

\section{Apresentação e análise dos resultados}

Nesta etapa, inicia-se o detalhamento dos dados obtidos por meio da coleta de dados proposta na metodologia. O primeiro conjunto de dados refere-se ao acompanhamento das postagens efetuadas no Twitter da empresa. O perfil foi acompanhado no período de 17 de março de 2010 a 17 de maio de 2010. Neste intervalo, foram registradas 70 postagens (tweets), sendo: 29 com links para o blog da Melissa; 21 com links de fotos; 12 com links direcionando para blogs e sites de terceiros que falavam sobre a marca Melissa; cinco com links de vídeos para o canal da Melissa no Youtube; e três com links para o site institucional da Melissa. Observou-se também que do total de postagens, oito falavam sobre o concurso cultural Melisseiras Et Circenses lançado no dia 11 de maio de 2010 e que terminou no dia 08 de junho de 2010. Nesta promoção, a Melissa convidava as melisseiras (fãs da marca) a enviar vídeos de até dois minutos com habilidade em alguma performance circense, relacionando com o tema da última coleção e desta forma, mostrando sua paixão pela marca Melissa. Também foi observado: 19 retweets gerais (RT); 77 retweets (RT) de postagens da loja virtual da Melissa (@LojaMelissa); 39 retweets (RT) com reply, ou seja, com comentários; e 47 replys (respostas para os seguidores). A segunda parte dos dados foi obtida por meio de entrevista realizada usando-se correio eletrônico. Foram enviados três questionários nos dias 04 de maio de 2010, 26 de maio de 2010 e 11 de junho de 2010. Estes questionários não estruturados, que se complementavam e eram 
Estudos em Jornalismo e Mídia - Vol. 9 № 2 - Julho a Dezembro de 2012

constituídos por cinco perguntas abertas em cada, foram respondidos por Caroline Kubbe, Gerente de Mídias Sociais da empresa Grafia, agência digital que atende a marca e que autorizou a publicação dos dados. Para finalizar esta parte de coleta de dados, foi fornecido pela empresa um briefing mostrando as características da marca, sua participação no mercado, descrição do produto, perfil do consumidor, comunicação e perguntas mais frequentes. Um histórico cronológico da Melissa foi disponibilizado como referência de análise.

A partir destes dados, pode-se observar como a Melissa trabalha a questão de fortalecimento de marca através do Twitter e quais são as estratégias definidas pela empresa para a sua atuação digital. Pelo acompanhamento do perfil no período de dois meses e pela entrevista concedida pela gerente de mídias sociais, os autores analisaram que o relacionamento é o pilar de sustentação das ações virtuais da empresa. Foi um total de 252 postagens, sendo que 182 diretamente se relacionavam de alguma forma com os seguidores, seja por retweets ou replys. As informações da empresa misturam-se à interação direta dos seguidores, criando uma base de dados relativos a esse público, pois opiniões são lidas e suas dúvidas solucionadas. O perfil @sigamelissa foi criado em 2008 e desde então os números de visitação do blog aumentaram de forma considerável. Em 2008, 0,29\% dos acessos eram de origem do Twitter. Em 2009, este numero subiu para 2,73\% e finalmente em 2010 (até o dia 30 de abril) o número de acessos proveniente do Twitter chegou aos 11,41\%. Os mesmos resultados positivos podem ser observados no acesso à loja virtual da Melissa. Em 2008, 3,94\% dos acessos eram de origem do Twitter. Em 2009 este número foi para 6,92\% e em 2010 (até o dia 30 de abril) para 13,48\%. Isto ajuda a comprovar a eficiência do Twitter trabalhado em conjunto com os outros recursos digitais ao gerar interação na comunicação e informação junto ao consumidor. Além do @sigamelissa, a marca também possui um perfil da loja virtual, o @lojamelissa, que de acordo com os dados analisados divulga lançamentos, promoções e informações relacionadas às vendas do produto em si. Essa divisão de papéis dentro do próprio Twitter é uma estratégia que segmenta e distribui melhor as funções de comunicação, além de proporcionar uma coleta de dados mais abrangente. Enquanto um perfil se preocupa com a parte dos negócios em si, a outra (@sigamelissa) foca nos desejos, nas expectativas através do relacionamento. Mesmo sendo utilizado muitas vezes como SAC, é neste perfil que a empresa estende seu conceito de marca, dando ao seguidor informações privilegiadas. Um dos pontos fortes conforme a análise feita são os tweets, pela qualidade das informações sobre o produto, 
Estudos em Jornalismo e Mídia - Vol. 9 № 2 - Julho a Dezembro de 2012

os serviços, lançamentos e promoções, e pela interação realizada com os seguidores. Além de replys, de responder as direct messages (DM), os retweets (RT) são feitos valorizando, na maioria das vezes, as fotos, comentários e elogios que as seguidoras mandam para o@sigamelissa. Isso é fundamental porque os tweets não são simples informações institucionais, eles mostram que existe uma presença humana do outro lado. Esta presença interage não só prestando um serviço de informação, mas também emite opinião, está conectada com os últimos acontecimentos da moda, com os assuntos mais populares de relevância nacional e principalmente, expressa emoção. Tudo alinhado com a política da empresa, porém dentro dos padrões atuais de relacionamento virtual. Um exemplo foi o lançamento da promoção Melisseiras Et Circenses lançada no dia 11 de maio de 2010. Mesmo em poucos dias de existência, observou-se a participação dos seguidores, se envolvendo de forma emocional com o concurso. Aliás, isso é um fator constante nas mensagens enviadas para o Twitter@sigamelissa. Percebeu-se que os consumidores conseguiram encontrar um canal do qual podem expressar sua paixão pela marca e ter seu sentimento valorizado.

Ainda que os resultados deste relacionamento sejam positivos, a empresa não planejou sua estratégia digital voltada para o relacionamento como fortalecimento da marca. Isso foi acontecendo aos poucos, de forma natural. A ambientação e interação virtual mostraram que isso era possível. Tinha-se uma ideia generalizada de que o Twitter como mídia social poderia auxiliar nesse aspecto, mas não houve um planejamento específico voltado para este objetivo, de acordo com a análise que se pode fazer com os dados obtidos e observados. Algumas questões de marketing no Twitter foram deixadas de lado como, por exemplo, a melhor utilização do background do perfil. No momento do estudo, o background do@sigamelissa era um fundo preto. Segundo a entrevistada, ele estava de acordo com o site institucional da empresa, porém não se verificou nenhuma informação relevante sobre a marca com este tipo de fundo. Falta até uma identificação com a proposta da marca que é conceito, inovação, moda e design. Outra questão que não ficou muito clara durante o estudo foi a utilização de aplicativos e métodos de rastreamento de tweets e monitoramentos de resultados por parte da Melissa. Esses fatores são fundamentais para medir a eficiência de um Twitter institucional na rede e segundo a respondente, estas informações não poderiam ser disponibilizadas, por questões de sigilo. Apenas vagamente foi informado que se utiliza um software para rastreamento de tweets, porém não houve detalhes sobre os aplicativos 
Estudos em Jornalismo e Mídia - Vol. 9 № 2 - Julho a Dezembro de 2012

usados para medir o retorno da estratégia empregada, como é feita esta medição qualitativa e quantitativa dos resultados obtidos.

Foi observado que a empresa utiliza o Twitter com o objetivo de divulgar lançamentos, informações, promoções, eventos, também como um canal para sanar dúvidas. O ideal seria potencializar algumas estratégias para que este trunfo de relacionamento seja mais bem aproveitado para fortalecer a marca, renovando seus conceitos, promovendo tendências e sendo uma referência de inovação no tratamento da solidificação da imagem no mercado.

\section{Considerações finais}

Percebeu-se que o Twitter é uma das mídias sociais que mais contribui para que as empresas estreitem relações com seus públicos-alvo e tenham um instrumento de fortalecimento de marca. Observa-se neste estudo, que para se conseguir resultados positivos não basta boa vontade, e sim uma estratégia bem estruturada, mesmo que ainda não se conheçam maneiras completamente testadas no mercado e na academia. É importante que os tweets sejam escritos por pessoas, para que haja um diálogo interativo e não apenas mensagens corporativas automáticas. O grande diferencial do Twitter é a possibilidade do relacionamento em tempo real, um canal direto entre empresa e consumidor, e medir o poder de influência da marca. É um canal que deve levar ao consumidor o ideal da empresa e as potencialidades do produto, incentivando desta forma, o bom relacionamento no mundo real. O consumidor tem que se sentir seguro em confiar numa organização que se preocupa em bem atendê-lo além das fronteiras da web. Outra medida importante é o planejamento de conteúdo, sabendo aproveitar e avaliar todas as oportunidades oferecidas como os Trending Topics (TTs), ou os tópicos mais populares do Twitter. Se a empresa tiver perspicácia e souber associar um assunto do momento com a marca será de muita valia, pois a deixará em evidência. Portanto, uma série de pequenos fatores precisa ser considerada para que o microblog seja um agente de fortalecimento da marca. As informações colocadas nele têm que ser interessantes e acima de tudo, inéditas. Informação privilegiada é um trunfo desta ferramenta que chega estar à frente de outros meios de comunicação.

Devido à produção colaborativa, o microblog passa a ser o instrumento favorito da nova geração de consumidores ávidos por conteúdo rápido, de fácil digestão e que possam compartilhar, multiplicando o alcance da informação. O Twitter oferece às empresas uma enorme oportunidade de promoção da marca, além de fazer um 
Estudos em Jornalismo e Mídia - Vol. 9 № 2 - Julho a Dezembro de 2012

acompanhamento em tempo real da percepção sobre sua atuação. Porém, vale lembrar que os riscos também estão inseridos nesta opção e a organização deverá estar atenta sobre uma possível repercussão negativa da marca ou mesmo crise. A relevância do marketing digital é a possibilidade de fazer o consumidor se sentir parte integrante do processo comunicacional, conferindo a ele um papel de crítico sobre a empresa. Esta valorização do relacionamento provoca um sentimento de exclusividade, de respeito pela opinião daqueles que transformam um simples produto num estilo de vida. Essa sensação de fazer parte de uma comunidade é uma das principais funções do microblog. Deve-se considerar que o Twitter não é uma rede social de amigos, mas sim de ideias, de grupos com gostos similares, com assuntos afins. E se uma empresa souber captar seguidores que possuem interesse nas suas ideias, nos seus bens e serviços, além de construir uma comunidade forte, de criar vendas diretas, ela também estará fortalecendo sua marca. Mas não basta somente ser criativo, ter bons tweets, criar diálogo com os seguidores e fazer promoções, ofertas especiais para se obter o melhor retorno do Twitter. É necessário montar a estratégia de acordo com o perfil da empresa, da marca e depois com observação, controle de dados e pesquisa (quantitativa e qualitativa) pode-se analisar se o objetivo foi alcançado ou não. As ações ainda são de erros e acertos, baseadas na intuição do profissional responsável, no estudo de casos, na observação do mercado e na aplicação de alguns conceitos de mídias tradicionais. Faltam pesquisas para subsidiar as ideias e ações. Este é o momento de criação de sustentação estratégica e novos estudos devem ser empreendidos pela academia. Como visto no estudo de caso, o perfil@sigamelissa da Melissa é um caso positivo, apesar de apresentar algumas lacunas no planejamento.

A empresa conseguiu melhoras no relacionamento, e consequentemente, o fortalecimento da marca. Os números comprovam esta eficiência. Dos 252 tweets analisados em dois meses, 182 geraram relacionamento em alguma instância e 86 são replys, respostas diretas aos seguidores. E neste período não foi observada em nenhum momento alguma crise de relacionamento, nem mesmo insatisfação sobre o produto. Pelo contrário. Ficou registrado um retorno positivo demonstrado na paixão e carinho pela marca por parte dos seguidores. Nesta pesquisa não se pretendeu enfatizar uma análise profunda do uso do marketing, nem mesmo do marketing de relacionamento, focando-se, sim, na utilização do microblog como uma estratégia de comunicação para fortalecimento de marca. Pode-se ter aí, no entanto, um limitador, mas foi deliberadamente definido pelos autores. Outro limitador foi a decisão de não se 
investigar mais de um perfil no Twitter, optando-se por uma análise profunda de um único caso, o que trouxe ganho para os resultados. Sugere-se para novos estudos uma análise de casos múltiplos de base comparativa. Outra opção, que pode ser um limitador, foi não se buscar informações diretamente com os seguidores que utilizaram essa ferramenta de comunicação, o que pode ser aproveitado, também, para estudos futuros.

Portanto, o Twitter mostrou-se eficaz no fortalecimento da marca do caso estudado. Com a análise percebeu-se que a estratégia de relacionamento é o diferencial para a manutenção da imagem da marca e que seus resultados podem servir como base teórica para a gestão do planejamento de marketing digital em mídias sociais. Empresas como a Melissa mostram ao mercado como se lida com a questão da constante renovação dos fundamentos empresariais nos tempos da era digital e do consumismo informacional.

\section{Referências}

@sigamelissa. Disponível em: <http://twitter.com/\#!/sigamelissa>. Acesso em: 26 abr. 2011. BERNARDO, A.; SPECK, F. What are you doing?: Uma reflexão sobre o Twitter. Estudos em Jornalismo e Mídia, Florianópolis, v. VII, n. 1, p. 74-96, Janeiro a Junho, 2010.

BRETZKE, M. Marketing de relacionamento e competição em tempo real. São Paulo: Atlas, 2000.

BULleT, Agência de Marketing Promocional. Pesquisa Twitter no Brasil, abril 2009. Disponível em: $<$ http://bullet.updateordie.com/insights/2009/06/bullet-divulga-o-resultado-da-primeira-pesquisabrasileira-realizada-no-twitter-2/>. Acesso em: 07 fev. 2011.

BURTON, S.; SOBOLEVA, A. Interactive or reactive? Marketing with Twitter. Journal of Consumer Marketing, v. 2, n. 7, p. 491-499, 2011.

CAMPOMAR, M. C. Do uso de "estudo de caso" em pesquisas para dissertações e teses em administração. Revista de Administração, São Paulo, v. 26, n. 3, p. 95-97, julho/setembro, 1991.

CARDOZO, M. L. Twitter: microblog e rede social. caderno.com, v. 4. N. 2, s. p., $2^{\circ}$ semestre, 2009.

CARVALHO, L. M. O Microblog Twitter como Agregador de Informações de Relevância Jornalística. Anais... Trabalho apresentado no GP Cibercultura, IX Encontro dos Grupos/Núcleos de Pesquisas em Comunicação, evento componente do XXXII Congresso Brasileiro de Ciências da Comunicação, Curitiba, 04 a 07 de setembro de 2009. Disponível em: $<$ http://www.intercom.org.br/papers/nacionais/2009/resumos/R4-3318-1.pdf > Acesso em: 05 fev. 2010. ClARO, J. A. C. S.; TORRES, M. O. F.; JOÃO, B. N.; TINOCO, J. E. P. Estilo de Vida do Jovem da "Geração Y" e suas Perspectivas de Carreira, Renda e Consumo. Anais... XIII Semead - Seminários em Administração. São Paulo: USP, Setembro de 2010. Disponível em: $<$ http://www.ead.fea.usp.br/semead/13semead/resultado/an_resumo.asp?cod_trabalho=671 $>$. Acesso em: 26 abr. 2011.

COMM, J.; BURGE, K. O poder do Twitter: estratégias para dominar seu mercado e atingir os seus objetivos com um tweet por vez. São Paulo: Gente, 2009.

CONSONI, G. B.; OIKAWA, E. A representação dos profissionais de comunicação no Twitter: Análise dos perfis de Marcelo Tas e Edney Souza, Curitiba, 04 a 07 de setembro de 2009. Anais... Intercom. Disponível em: <http:/www.intercom.org.br/papers/nacionais/2009/resumos/R4-1966-1.pdf>. Acesso em: 06 fev. 2011.

DE SALVI, R. É só twittar e seguir os passos: nova rede social na internet cria oportunidades de relacionamento com o consumidor. Revista Eletrônica Propaganda, 15 de setembro de 2009. Disponível em: <http://www.revistapropaganda.com.br/materia.aspx?m=336>. Acesso em: 10 out. 2009. 
DIAS, C.; COUTO, O. F. As redes sociais na divulgação e formação do sujeito do conhecimento: compartilhamento e produção através da circulação de ideias. Linguagem em (Dis)curso, Tubarão, SC, v. 11, n. 3, p. 631-648, set./dez., 2011.

DOMINGUES, D. M. G. Ciberespaço e rituais: tecnologia, antropologia e criatividade. Horizontes Antropológicos, Porto Alegre, v. 10, n. 21, p. 181-198, jan/jun, 2004.

GARBIN, E. M. Cultur@s juvenis, identid@des e internet: questões atuais. Revista Brasileira de Educação, Rio de Janeiro, n. 23, p. 119-135, maio/jun/jul/ago., 2003.

HENDERSON, K. Using Twitter for B-to-B Marketing. Revista Eletrônica Phone+, 21 de janeiro de 2010 .

KOTLER, P. Administração de marketing. 12. ed. São Paulo: Prentice-Hall, 2006.

LAB SSJ, Laboratório de negócios: pesquisa e desenvolvimento de pessoas. Geração Y: Perspectivas sobre o ambiente multigeracional. Fevereiro 2010. Disponível em: $<$ http://www.ssj.com.br/criacao/Pocket4_GeracaoYweb.pdf >. Acesso em: 27 mai. 2010.

LEVY, P. O que é virtual?. São Paulo: 34, 1996.

Cibercultura. São Paulo: 34, 1999.

McKENNA, R. Marketing de relacionamento. Rio de Janeiro: Campus, 1999.

MÍDIAS SOCIAIS. Blog especializado em mídias sociais. Disponível em: $<$ http://www.midiassociais.net/>. Acesso em: 22 abr. 2010.

RODRIGUEZ, N. X. Percepção dos usuários da rede social Twitter com relação às estratégias de comunicação dos grupos de notícias, GP Conteúdos Digitais e Convergências Tecnológicas, Anais... IX Encontro dos Grupos/Núcleos de Pesquisas em Comunicação, evento componente do XXXII Congresso Brasileiro de Ciências da Comunicação, Belo Horizonte, 05 junho 2009, 2009.

SILVA, H. S.; VALLS, V. M. Retenção de conhecimento na Internet: o papel do Twitter. CRB-8 Digital, São Paulo, v. 1, n. 5, p. 124-147, jan., 2012.

THORING, A. Corporate tweetting: Analysing the Use of Twitter as a Marketing Tool by UK Trade Publishers. Pub Res Q. v. 27, p. 141-158, 2011.

TWITTER. Disponível em: <www.twitter.com>. Acesso em: 13 mar. 2012.

VELLOSO, R. V. O ciberespaço como ágora eletrônica na sociedade contemporânea. Ci. Inf., Brasília, v. 37, n. 2, p. 103-109, maio/ago., 2008.

WHEELER, A. Design de identidade de marca: guia essencial para toda a equipe de gestão de marcas. $3^{\text {a }}$. Ed. Porto Alegre: Bookman, 2012.

YIN, R. K. Estudo de Caso: Planejamento e métodos. Porto Alegre: Bookman, 2005.

ZAGO, G. S. Dos blogs ao microblogs: aspectos históricos, formatos e características, Niterói, Rio de Janeiro, Anais... GT História da Mídia Digital do VI Congresso Nacional de História da Mídia, 13 e 16 de maio 2008. Disponível em: < http://www.bocc.uff.br/pag/zago-gabriela-dos-blogs-aos-microblogs.pdf>. Acesso em 04 fev. 2010.

Este artigo e todo o conteúdo da Estudos em Jornalismo e Mídia estão disponíveis em http://www.periodicos.ufsc.br/index.php/jornalismo/index

Estudos em Jornalismo e Mídia está sob a Licença Creative Commons. 